\title{
Incidence of post-obturation pain after single-visit versus multiple-visit non-surgical endodontic treatments
}

\author{
Amy Wai-Yee Wong ${ }^{1}$, Shinan Zhang ${ }^{1 \dagger}$, Samantha Kar-Yan $\mathrm{Li}^{1+}$, Xiaofei Zhu ${ }^{2^{*}}$, Chengfei Zhang ${ }^{1{ }^{*+}}$ \\ and Chun-Hung $\mathrm{Chu}^{1+}$
}

\begin{abstract}
Background: Post-obturation pain is frustrating to both patients and dentists. Its incidence may change with the use of contemporary endodontic techniques. This randomised clinical trial aims to compare the incidence of post-obturation pain at one and seven days after single-visit and multiple-visit non-surgical endodontic treatments.
\end{abstract}

Methods: Patients who required primary endodontic treatment in the two clinical trial centres in Hong Kong $(H K)$ and in Beijing (PK) were recruited. Three HK dentists and three PK dentists performed endodontic treatments on 567 teeth using the same procedures and materials, either in a single visit or over multiple visits, using either core carrier or cold lateral condensation for obturation.

Results: The attrition rate was $5.1 \%$, and a total of 538 teeth were evaluated. Among these teeth, $232(43 \%)$ were operated in HK, 275 (51 \%) were treated in a single visit, and 234 (43\%) were treated using core carrier obturation. Logistic regression analysis showed that teeth with apical periodontitis $(\mathrm{OR}=0.35,95 \% \mathrm{Cl}=0.21-0.57, p<0.01)$ and less pre-operative pain $(\mathrm{OR}=1.10,95 \% \mathrm{Cl}=1.03-1.18, p<0.01)$ had lower incidences of post-obturation pain after one day. The incidences of post-obturation pain after one day for single-visit and multiple-visit treatments were $24.7 \%$ (68 of 275) and $33.5 \%$ (88 of 263), respectively $(p=0.50$ ). The incidences of post-obturation pain after seven days for single-visit and multiple-visit treatments were $4.0 \%$ (11 of 275 ) and $5.3 \%$ (14 of 263), respectively ( $p=0.47$ ).

Conclusions: There was no significant difference in the incidences of post-obturation pain after one day and seven days with single-visit or multiple-visit endodontic treatments.

Trial registration: ChiCTR-IOR-15005989

\section{Background}

Patients commonly complain of post-obturation discomfort and pain after endodontic (root canal) treatments, which can upset both clinicians and patients. The pain intensity can range from mild to severe, and it is widely described as occurring in flare-ups. The duration of the pain can range from one day to several weeks and can be a major cause of patient dissatisfaction. In addition, post-obturation pain after endodontic treatment is a poor indicator of pathosis and an even more unreliable

\footnotetext{
* Correspondence: zhuxiaofei767@foxmail.com; cfzhang@hku.hk

${ }^{\dagger}$ Equal contributors

${ }^{2}$ VIP Dental Service \& Geriatric Dentistry, School and Hospital of Stomatology, Peking University, Beijing, China

${ }^{1}$ Faculty of Dentistry, The University of Hong Kong, Hong Kong, China
}

predictor of long-term success [1]. The reported findings on post-obturation pain differ between studies. A systematic review found that it occurs in around 4 to $10 \%$ of patients, in general [2]. However, DiRenzo and colleagues reported in their review that the incidence of post-obturation pain after non-surgical endodontic treatment can be greater than $50 \%$ [1].

Endodontic treatment once necessitated multiple visits, as it required a considerable amount of time to complete [2]. Multiple-visit root canal treatment is accepted as a safe and common therapy. However, the rationale for multiple-visit endodontic treatment is being questioned. A systematic review found no significant differences between the antimicrobial efficacies reported for single-visit and 
multiple-visit treatments [2]. In addition, the use of contemporary endodontic techniques and equipment, such as magnifying devices, electronic apex locators, and enginedriven rotary nickel titanium files, not only increases the success rate of endodontic treatment but also shortens the time needed for treatment [3].

Cold lateral condensation (CLC) using gutta-percha is a commonly taught method of obturation. Dental practitioners use it often, and it frequently serves as a basis of comparison for new obturation techniques [4]. The core carrier obturation technique has become popular since its introduction in late 1980s, as studies have generally found that it as effective as CLC for root canal obturation [4-6]. In addition, many clinicians consider it to be fast, predictable, easy to use, effective, and useful for small, curved, or densely packed canals [7]. The Thermafil (TF) obturator (Dentsply Maillefer, Ballaigues, Switzerland) is a typical product used in core carrier obturation [4]. Gencoglu compared the apical sealing of obturation with TF and CLC and found that TF was better than CLC [8]. Studies have also suggested that core carrier obturation is more effective than CLC at filling lateral canals $[9,10]$. Furthermore, TF was shown to have less leakage than CLC $[8,11]$.

If the incidence and intensity of post-obturation pain and the long-term success rate for single-visit and multiple-visit endodontic treatments are similar, singlevisit treatment can be considered to be the more comfortable and efficient option. The aim of this study was to compare the incidence of post-obturation pain at one and seven days after single-visit and multiple-visit primary non-surgical endodontic treatments. The primary outcome measured was the incidence of post-obturation pain. The secondary outcome measured was the intensity of post-obturation pain. The first hypothesis is that there is no difference in the incidence of post-obturation pain for single-visit and multiple-visit non-surgical endodontic therapies one day after obturation; the second hypothesis is that there is no difference in the incidence of post-obturation pain for single-visit and multiple-visit nonsurgical endodontic therapies seven days after obturation.

\section{Methods}

\section{Patient recruitment}

The study was approved by the Institutional Review Board of the University of Hong Kong/Hospital Authority Hong Kong West Cluster (HKU UW 09 - 303) in Hong Kong and the Institutional Review Board of Peking University (PKU IRB 00001052 - 10071) in Beijing, China. The study is registered at the World Health Organization's International Clinical Trials Registry Platform (Clinical trial registration no.: ChiCTR-IOR-15005989). Chinese patients aged 18 or above who were generally healthy and required primary endodontic treatment via the University of Hong Kong (HKU) Health Service Dental Clinic or the
Peking University (PKU) School and Hospital of Stomatology Special Service Clinic in Beijing were invited to participate in the study. Teeth with pulpotomy were not accepted, and at least half of the coronal structure had to be present. The protocol of the study was explained to the participants, and consent was obtained. Patients who had severe acute pulpitis, facial swelling or systemic infection, severe systemic disease, increased stress on the temporomandibular joint musculature, or increased psychological stress were excluded from this study.

Participants were scheduled for endodontic treatment. The preoperative clinical signs were recorded, including the presence of apical periodontitis (via the presence of apical radiolucency in the radiograph), chronic apical abscesses with or without the sinus tract, tooth mobility (MII, i.e., $1 \mathrm{~mm}$ horizontal mobility or above), tenderness to percussion, pockets, and preoperative pain. The pain assessment was adapted from our previous study [12], which measured pain on a 10-point Likert scale, ranging from no pain (score 0) to extreme pain (score 10), as shown in Fig. 1. Patients were reviewed one week after the obturation of the root canals, during which the presence of the clinical signs mentioned above were assessed and recorded. They were also asked about their 1-day and 7-day post-obturation pain, using assessment scale mentioned above (Fig. 1). Figure 2 is the study's flow chart.

\section{Sample size calculation}

The primary outcome measured was the prevalence of post-obturation pain, which was used to calculate the sample size. The prevalence of post-obturation pain was estimated at $10 \%$. We considered a difference of at least $10 \%$ between single-visit and multiple-visit endodontic treatments to be clinically significant and statistically achievable. The estimated sample size was based on the expected prevalence of post-obturation pain, with the power of the study set at $80 \%(\beta=0.20)$ and with $\alpha=0.05$

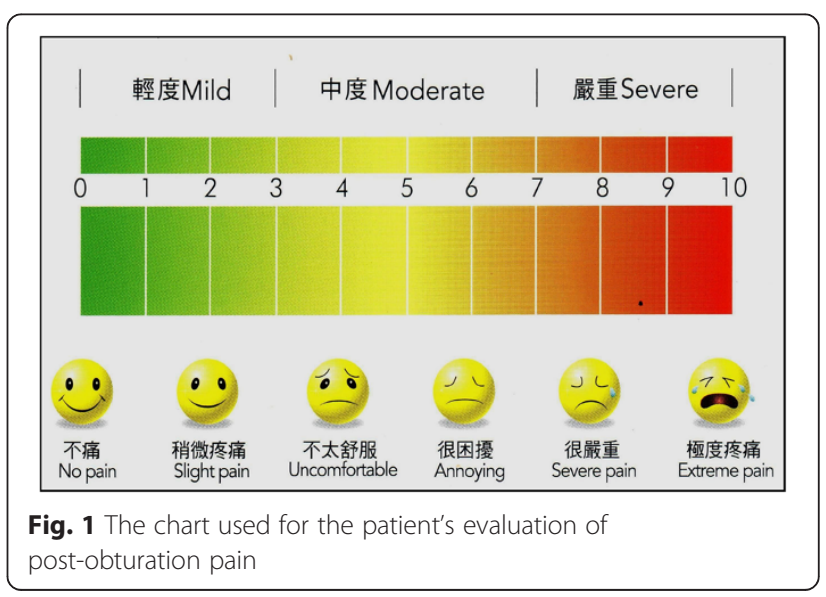




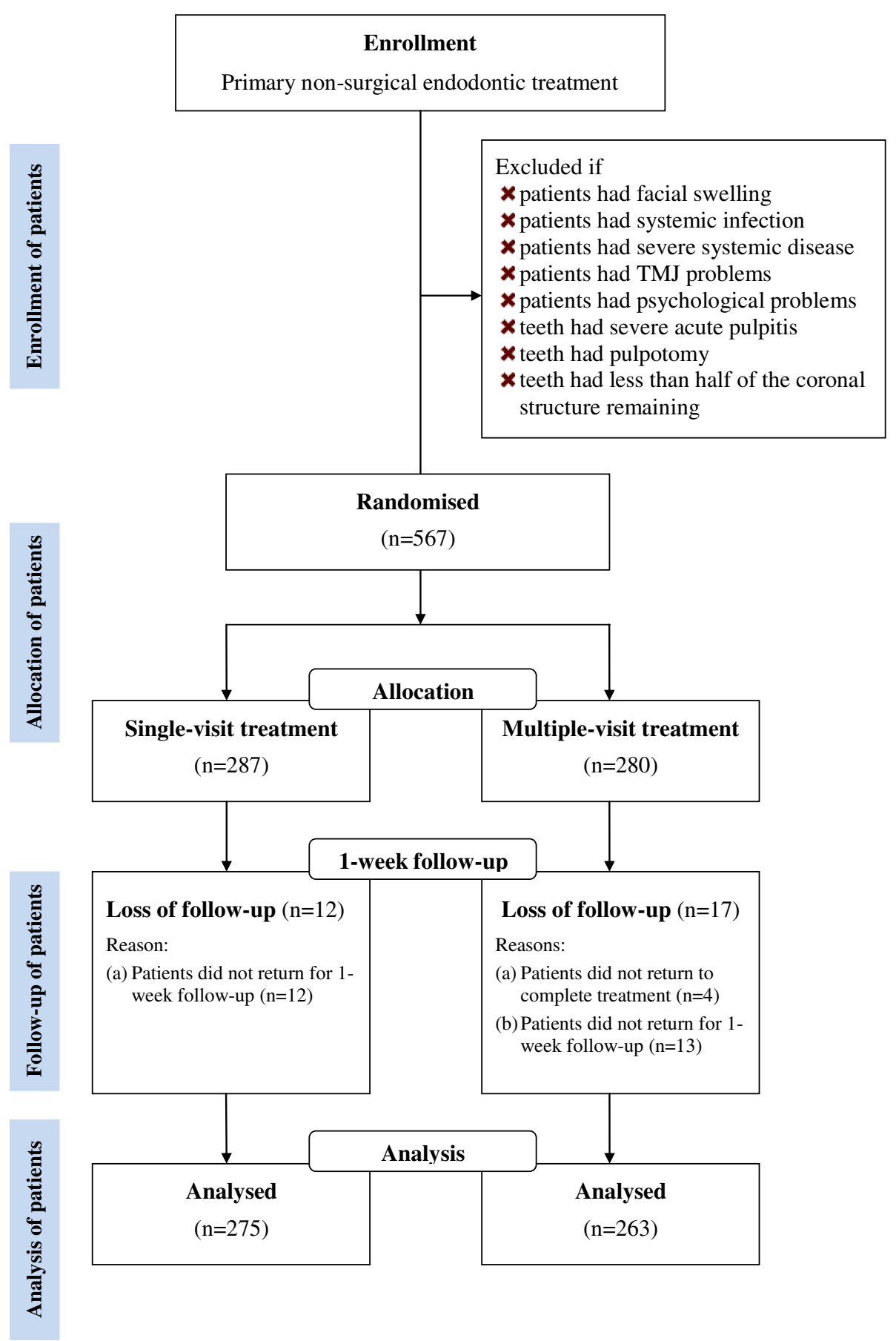

Fig. 2 The study's flow chart

as the significance level. Using the software program G*Power, version 3.1.7 (Franz Faul, Kiel University, Germany), we calculated that at least 199 teeth would be required per study group. We estimated the response rate to be $85 \%$ and therefore aimed to recruit at least 230 teeth per group in this study.

\section{Clinical procedure}

Three dentists from HKU and three dentists from PKU formed three pairs of dentists with similar clinical experience, to carry out the endodontic treatments. One dentist from each pair was trained to use the magnifying loupe $(2.5 \times)$. All six dentists performed standardised 
endodontic treatments, which were done over either a single visit or multiple visits, and the obturations were performed with either CLC or TF. Receptionists randomly assigned patients to the dentists for treatment using the random-number generating function of a calculator. The dentists received a training workshop prior to this clinical trial to standardise their instrumentation and obturation technique, as described below. Local anaesthetic was given, and a rubber dam was used for isolation. The access cavity was prepared with a glide path before the use of rotary instruments. The root canals were prepared using a crown-down technique, which prepares the coronal part of the canal before the apical portion to achieve a straight-lined access for rotary nickel-titanium endodontic files (ProTaper Universal, Dentsply Maillefer, Ballaigues, Switzerland). Sodium hypochlorite solution at $5.25 \%$ combined with a chelating agent of 17 \% EDTA solution was used for irrigation. EDTA $15 \%$ lubricant (RCPrep, Premier, Philadelphia, USA) was used in the shaping procedures [13]. The working length was measured by an electronic apex locator (Root ZX, J Morita, Kyoto, Japan). The apical third of the canals was instrumented with F2 file with a diameter \#25 at its tip. The canal was obturated after preparation if the tooth was assigned to the single-visit group. Otherwise (for the multiple-visit group), non-setting $35 \%$ calcium hydroxide paste (UltraCal XS, Ultradent, South Jordan, UT, USA) was used as inter-appointment medication. The tooth was temporarily restored with resinmodified zinc oxide and eugenol cement (IRM, LD Caulk Dentsply, Milford, CT, USA) until obturation. The prepared tooth was obturated on the subsequent visit, which was usually seven days later. The root-canal sealer (AH Plus, Dentsply DeTrev GmbH, Konstanz Germany) was applied prior to obturation with either TF or CLC. The obturated teeth were then sealed with resin-modified zinc oxide and eugenol cement on the same visit. All the treated teeth, including single-rooted and multi-rooted teeth, received the same procedures.

\section{Data analysis}

The collected data were entered into a personal computer and analysed with the IBM SPSS Statistics 21.0 program (Armonk, NY, USA). The primary outcome of this research was to evaluate the prevalence of pain at one day and seven days after obturation among the single-visit and multiple-visit treatment groups. The following possibly related independent variables were also considered: patients' age and gender (male or female), tooth vitality (vital or non-vital), number of canals (single or multiple), tooth position (anterior or posterior), arch (upper or lower), obturation method (CLC or TF), use of magnifying loupe (yes or no), status of opposing tooth (yes or no), abscess or sinus tract (yes or no), tender to percussion (yes or no), tooth hypermobility (yes or no), periodontal pocket (yes or no), apical periodontitis (yes or no), C-shaped canal (yes or no), operator's experience $(\leq 10$ years or $>10$ years), intensity of preoperative pain (0 to 10), and treatment time. For the categorical independent variables, separated chi-square tests were used to assess the differences in the prevalence of pain among the groups. For the continuous independent variables, separated two-sample t-tests were used to assess the mean difference between the groups with and without post-obturation pain. The significant factors in the above tests $(p<0.05)$ were assessed using multiple logistic regression to investigate their relationships with post-obturation pain after one day and after seven days.

Separated analysis of variance (ANOVA) regression models were used to study the relationships between the intensity of post-obturation pain among the treatment group and the previously mentioned independent variables. The significant variables $(p<0.05)$ were then entered into the ANCOVA model for analysis. The level of statistical significance was set at $5 \%$, and all of the statistical analyses involved 2-tailed tests.

\section{Results}

A total of 538 out of 567 teeth were evaluated, with 275 teeth $(51 \%)$ receiving single-visit endodontic treatment. Table 1 shows the descriptive statistics for the independent variables according to treatment group. The mean $( \pm \mathrm{SD})$ age of the patients was $46.5 \pm 17.0$, and $305(57 \%)$ were female. Among the 538 teeth, 219 (41\%) were vital, $219(41 \%)$ had a single root canal, 135 (25\%) were anterior (incisors or canines), 25 (5\%) had no opposing teeth, and 320 (59 \%) were in the upper arch. There were 210 teeth $(39 \%)$ with apical periodontitis, 182 (34 \%) that were tender to percussion, $57(11 \%)$ with a periodontal pocket at least $4 \mathrm{~mm}$ in depth, $50(9 \%)$ with a sinus tract or abscess, $22(4 \%)$ with a C-shaped canal, and $18(3 \%)$ with at least MII mobility. There were 306 teeth (57 \%) done in PKU, 234 (43\%) obturated using TF, 243 (45 \%) treated using loupes, and 309 (57 \%) treated by dentists with less than or equal to 10 years of experience.

Post-operative pain was found in 156 teeth (29\%) after one day. Most of the pain reported was mild to moderate both after one day $(n=149 / 156,96 \%)$ and after seven days $(n=23 / 25,92 \%)$. Table 2 shows the incidence of post-obturation pain after one day and seven days along with other variables. Teeth that were treated in a single visit were obturated with TF, were treated by an operator with $>10$ years' experience, had apical periodontitis, were non-vital, and had lower levels of pre-operative pain all showed lower incidences of post-obturation pain after one day. Only 25 teeth (5\%) had post-obturation pain after seven days, and 21 of them were upper teeth. The post- 
Table 1 Independent variables according to treatment groups (*Significant result, $p<0.05$ )

\begin{tabular}{|c|c|c|c|c|}
\hline \multirow[t]{3}{*}{ Independent variable } & \multirow[t]{3}{*}{ Category } & \multirow{2}{*}{$\begin{array}{l}\text { Single-visit } \\
(n=275)\end{array}$} & \multirow{3}{*}{$\begin{array}{l}\text { Multiple-visit } \\
(n=263) \\
\text { No. (Col \%) }\end{array}$} & \multirow[t]{3}{*}{$p$-value } \\
\hline & & & & \\
\hline & & No. (Col \%) & & \\
\hline \multirow[t]{2}{*}{ Obturation method } & Thermafil & $155(56 \%)$ & $79(30 \%)$ & \multirow[t]{2}{*}{$<0.01^{*}$} \\
\hline & Lateral condensation & $120(44 \%)$ & $184(70 \%)$ & \\
\hline \multirow[t]{2}{*}{ Use of loupe } & Yes & 104 (38 \%) & 139 (53 \%) & \multirow[t]{2}{*}{$<0.01^{*}$} \\
\hline & No & $171(62 \%)$ & $124(47 \%)$ & \\
\hline \multirow[t]{2}{*}{ Operator's experience } & $<=10$ years & $121(44 \%)$ & 188 (71 \%) & \multirow[t]{2}{*}{$<0.01^{*}$} \\
\hline & $>10$ years & $154(56 \%)$ & 75 (29 \%) & \\
\hline \multirow[t]{2}{*}{ Gender } & Male & $131(48 \%)$ & 102 (39 \%) & \multirow[t]{2}{*}{$0.04^{*}$} \\
\hline & Female & $144(52 \%)$ & 161 (61\%) & \\
\hline \multirow[t]{2}{*}{ Arch } & Upper & $172(63 \%)$ & 148 (56 \%) & \multirow[t]{2}{*}{0.14} \\
\hline & Lower & $103(37 \%)$ & 115 (44 \%) & \\
\hline \multirow[t]{2}{*}{ Tooth position } & Anterior & $92(33 \%)$ & $43(16 \%)$ & \multirow[t]{2}{*}{$<0.01^{*}$} \\
\hline & Posterior & $183(67 \%)$ & $220(84 \%)$ & \\
\hline \multirow[t]{2}{*}{ Canal } & Single & $142(52 \%)$ & 77 (29 \%) & \multirow[t]{2}{*}{$<0.01^{*}$} \\
\hline & Multiple & $133(48 \%)$ & 186 (71 \%) & \\
\hline \multirow[t]{2}{*}{ C-shaped canal } & Yes & $5(2 \%)$ & $17(6 \%)$ & \multirow[t]{2}{*}{$0.01^{*}$} \\
\hline & No & 270 (98\%) & 246 (94\%) & \\
\hline \multirow[t]{2}{*}{ Periodontal pocket } & Yes & 25 (9\%) & $32(12 \%)$ & \multirow[t]{2}{*}{0.25} \\
\hline & No & $250(91 \%)$ & $231(88 \%)$ & \\
\hline \multirow[t]{2}{*}{ Apical periodontitis } & Yes & $110(40 \%)$ & 100 (38 \%) & \multirow[t]{2}{*}{0.64} \\
\hline & No & $165(60 \%)$ & $163(62 \%)$ & \\
\hline Tender to percussion & Yes & $74(27 \%)$ & 108 (41 \%) & $<0.01^{*}$ \\
\hline & No & $201(73 \%)$ & 155 (59 \%) & \\
\hline Hypermobility & Yes & $6(2 \%)$ & $12(5 \%)$ & 0.12 \\
\hline & No & $269(98 \%)$ & $251(95 \%)$ & \\
\hline Abscess or sinus tract & Yes & $23(8 \%)$ & $27(10 \%)$ & 0.45 \\
\hline & No & $252(92 \%)$ & $236(90 \%)$ & \\
\hline Tooth vitality & Vital & $101(37 \%)$ & $118(45 \%)$ & 0.05 \\
\hline & Non-vital & $174(63 \%)$ & $145(55 \%)$ & \\
\hline Opposing tooth & Yes & $261(95 \%)$ & $252(96 \%)$ & 0.62 \\
\hline & No & $14(5 \%)$ & $11(4 \%)$ & \\
\hline Post-operative pain after 1 day & Pain & $68(25 \%)$ & $88(33 \%)$ & $0.03^{*}$ \\
\hline & No pain & $207(75 \%)$ & 175 (67 \%) & \\
\hline Post-operative pain after 7 days & Pain & $11(4 \%)$ & $14(5 \%)$ & 0.47 \\
\hline & No pain & $264(96 \%)$ & $249(95 \%)$ & \\
\hline Independent variable & All cases & Single-visit & Multiple-visit & $p$-value \\
\hline & Mean (SD) & Mean (SD) & Mean (SD) & \\
\hline Treatment Time $(n=538)$ & $51.07(30.59)$ & $44.85(26.57)$ & $57.57(33.11)$ & $<0.01^{*}$ \\
\hline Pre-operative pain intensity $(n=538)$ & $2.04(2.93)$ & $1.18(2.32)$ & $2.93(3.23)$ & $<0.01^{*}$ \\
\hline Pain intensity after 1 Day $(n=156)$ & $3.26(1.72)$ & $2.81(1.54)$ & $3.61(1.78)$ & $<0.01^{*}$ \\
\hline Pain intensity after 7 Days $(n=25)$ & $2.60(1.92)$ & $1.64(0.67)$ & $3.36(2.24)$ & $0.02^{*}$ \\
\hline Age $(n=538)$ & $46.5(16.9)$ & $46.69(17.34)$ & $46.29(16.52)$ & 0.78 \\
\hline
\end{tabular}


Table 2 Independent variables and post-obturation pain incidence after 1 day and 7 days $(n=538)$

\begin{tabular}{|c|c|c|c|c|c|c|c|}
\hline \multirow[t]{2}{*}{ Independent variable } & \multirow[t]{2}{*}{ Category (No.) } & \multicolumn{3}{|c|}{ Incidence of pain after 1 day } & \multicolumn{3}{|c|}{ Incidence of pain after 7 days } \\
\hline & & No. & $\%$ & $p$-value & No. & $\%$ & $p$-value \\
\hline \multirow[t]{2}{*}{ Treatment visit } & Single (275) & 68 & $25 \%$ & $0.03^{*}$ & 11 & $4 \%$ & 0.47 \\
\hline & Multiple (263) & 88 & $33 \%$ & & 14 & $5 \%$ & \\
\hline \multirow[t]{2}{*}{ Obturation method } & Thermafil (234) & 47 & $20 \%$ & $<0.01^{*}$ & 10 & $4 \%$ & 0.72 \\
\hline & Lateral condensation (304) & 109 & $36 \%$ & & 15 & $5 \%$ & \\
\hline \multirow[t]{2}{*}{ Use of loupe } & Yes (243) & 74 & $30 \%$ & 0.50 & 10 & $4 \%$ & 0.59 \\
\hline & No (295) & 82 & $28 \%$ & & 15 & $5 \%$ & \\
\hline \multirow[t]{2}{*}{ Operator's experience } & $<=10$ years $(309)$ & 110 & $36 \%$ & $<0.01^{*}$ & 15 & $5 \%$ & 0.79 \\
\hline & $>10$ years $(229)$ & 46 & $20 \%$ & & 10 & $4 \%$ & \\
\hline \multirow[t]{2}{*}{ Gender } & Male (233) & 65 & $28 \%$ & 0.62 & 10 & $4 \%$ & 0.73 \\
\hline & Female (305) & 91 & $30 \%$ & & 15 & $5 \%$ & \\
\hline \multirow[t]{2}{*}{ Arch } & Upper (320) & 92 & $29 \%$ & 0.38 & 21 & $7 \%$ & $0.01^{*}$ \\
\hline & Lower (218) & 64 & $29 \%$ & & 4 & $2 \%$ & \\
\hline \multirow[t]{2}{*}{ Tooth position } & Anterior (135) & 34 & $25 \%$ & 0.26 & 5 & $4 \%$ & 0.55 \\
\hline & Posterior (403) & 122 & $30 \%$ & & 20 & $5 \%$ & \\
\hline \multirow[t]{2}{*}{ Canal } & Single (219) & 59 & $27 \%$ & 0.38 & 10 & $5 \%$ & 0.94 \\
\hline & Multiple (319) & 97 & $30 \%$ & & 15 & $5 \%$ & \\
\hline \multirow[t]{2}{*}{ C-shaped canal } & Yes (22) & 8 & $35 \%$ & 0.44 & 0 & $6 \%$ & $0.62^{\mathrm{a}}$ \\
\hline & No (516) & 148 & $24 \%$ & & 25 & $3 \%$ & \\
\hline \multirow[t]{2}{*}{ Periodontal pocket } & Yes (57) & 17 & $30 \%$ & 0.88 & 5 & $9 \%$ & $0.17^{\mathrm{a}}$ \\
\hline & No (481) & 139 & $29 \%$ & & 20 & $4 \%$ & \\
\hline \multirow[t]{2}{*}{ Apical periodontitis } & Yes (210) & 36 & $17 \%$ & $<0.01^{*}$ & 7 & $3 \%$ & 0.25 \\
\hline & No (328) & 120 & $37 \%$ & & 18 & $5 \%$ & \\
\hline \multirow[t]{2}{*}{ Tender to percussion } & Yes (182) & 60 & $33 \%$ & 0.15 & 13 & $7 \%$ & $0.05^{\mathrm{a}}$ \\
\hline & No (356) & 96 & $27 \%$ & & 12 & $3 \%$ & \\
\hline \multirow[t]{2}{*}{ Hypermobility } & Yes (18) & 5 & $28 \%$ & 0.91 & 3 & $17 \%$ & 0.05 \\
\hline & No (520) & 151 & $29 \%$ & & 22 & $4 \%$ & \\
\hline \multirow[t]{2}{*}{ Abscess or sinus tract } & Yes (50) & 10 & $20 \%$ & 0.14 & 4 & $8 \%$ & $0.28^{\mathrm{a}}$ \\
\hline & No (488) & 146 & $30 \%$ & & 21 & $4 \%$ & \\
\hline \multirow[t]{2}{*}{ Tooth vitality } & Vital (219) & 78 & $36 \%$ & $0.01^{*}$ & 12 & $5 \%$ & 0.45 \\
\hline & Non-Vital (319) & 78 & $24 \%$ & & 13 & $4 \%$ & \\
\hline \multirow[t]{2}{*}{ Opposing tooth } & Yes (513) & 150 & $29 \%$ & 0.57 & 24 & $5 \%$ & $1.00^{\mathrm{a}}$ \\
\hline & No (25) & 6 & $24 \%$ & & 1 & $4 \%$ & \\
\hline \multirow[t]{3}{*}{ Independent variable } & & \multicolumn{3}{|c|}{ Incidence of pain after 1 day } & \multicolumn{3}{|c|}{ Incidence of pain after 7 days } \\
\hline & & No $(n=382)$ & Yes $(n=156)$ & $p$-value & No $(n=513)$ & Yes $(n=25)$ & $p$-value \\
\hline & & Mean (SD) & Mean (SD) & & Mean (SD) & Mean (SD) & \\
\hline Age & & $46.9(17.2)$ & $45.4(16.1)$ & 0.36 & $46.5(16.9)$ & $46.4(17.9)$ & 0.97 \\
\hline Pre-operative pain intensity & & $1.7(2.7)$ & $2.8(3.2)$ & $<0.01^{*}$ & $2.0(2.9)$ & $2.4(2.8)$ & 0.57 \\
\hline Treatment time & & $52.5(31.3)$ & $47.6(28.4)$ & 0.09 & 50.7 (29.9) & $59.1(42.9)$ & 0.34 \\
\hline
\end{tabular}

${ }^{\mathrm{a}}$ Fisher's exact test; *Significant result, $\mathrm{p}<0.05$

obturation pain after seven days was not related to the number of treatment visits (chi-square test, $p=0.47$ ).

Multiple logistic regression (full model) showed that the number of treatment visits was not related to the incidence of post-obturation pain after one day when adjusting for other possible related variables (adjusted $p=0.50$ ) (Table 3). The incidence of post-obturation pain after one day was lower for teeth with the presence of apical 
periodontitis $(\mathrm{OR}=0.35,95 \% \mathrm{CI}=0.21-0.57, p<0.01)$. In addition, teeth with more intense pre-operative pain had increased incidence of post-obturation pain after one day $(\mathrm{OR}=1.10,95 \% \mathrm{CI}=1.03-1.18, p<0.01)$, with Nagelkerke R-squared $=0.11$.

Table 2 shows that the arch was the only significant variable associated with the incidence of post-obturation pain after seven days. Further simple logistic regression found that endodontically treated upper teeth had increased incidence of post-obturation pain after seven days $(\mathrm{OR}=3.76,95 \% \mathrm{CI}=1.27-11.10, p=0.02)$, with Nagelkerke R-squared $=0.04$.

Table 4 shows the factors related to pain intensity after one day in the separated unadjusted models and the adjusted model (a multi-way ANCOVA model). The mean $( \pm \mathrm{SD})$ pain intensity was $3.26 \pm 1.72$ among the 156 endodontically treated teeth with postobturation pain after one day. The post-obturation pain intensity was related to the treatment group, presence of an abscess or sinus tract, percussion tenderness, use of a magnifying loupe, obturation method, and intensity of the pre-obturation pain (Table 4). Multiple-way ANCOVA analysis found that multiple-visit endodontic treatment, presence of an abscess or sinus tract, obturation with TF, and more severe pre-operative pain showed increased intensity of post-obturation pain after one day.

Table 5 shows the factors related to pain intensity after seven days in separated, unadjusted models (ANOVA regression models). Among the 25 endodontically treated teeth with post-obturation pain after seven days, the mean score $( \pm \mathrm{SD})$ of the pain intensity was $2.60 \pm 1.92$.

Table 3 Multiple logistic regression on post-obturation pain incidence after 1 day $(n=538)$

\begin{tabular}{llccc}
\hline Independent variable & Category & $\begin{array}{l}\text { Odds } \\
\text { ratio }\end{array}$ & $95 \%$ C.I. & $p$-value \\
\hline Treatment visit & Single & 0.87 & $0.57-1.32$ & 0.50 \\
& Multiple & 1 & & \\
Obturation method & $\begin{array}{l}\text { Thermafil } \\
\text { Lateral }\end{array}$ & 0.38 & $0.04-3.85$ & 0.41 \\
& $\begin{array}{l}\text { condensation } \\
\text { Operator's experience }\end{array}$ & 1 & & \\
& $>10$ years & 0.68 & $0.07-7.12$ & 0.75 \\
Apical periodontitis & Yes years & 1 & & \\
& No & 0.35 & $0.21-0.57$ & $<0.01^{*}$ \\
Vitality & Vital & 0.67 & $0.40-1.11$ & 0.12 \\
& Non-Vital & 1 & & \\
$\begin{array}{l}\text { Pre-operative pain } \\
\text { intensity }\end{array}$ & $0-10$ & 1.10 & $1.03-1.18$ & $<0.01^{*}$ \\
\hline
\end{tabular}

Nagelkerke R-squared $=0.11 ;$ *Significant result, $p<0.05$
Teeth that received single-visit endodontic treatments were less painful after seven days $(p=0.02)$.

\section{Discussion}

Endodontic treatment is reasonable, based on the treatment cost; operators and patients consider it to be a practical clinical technique to resume the function of treated teeth [14]. Most patients are concerned about the pain encountered during and after endodontic treatment. Both patients and operators are keen to identify the factors that increase the probability of post-obturation pain. In treatment planning, it is helpful to be aware of the risks associated with post-treatment pain. Operators can prepare effectively via communication with patients before treatment and can also apply a different approach to deal with patients who experience post-obturation pain [15].

The null hypothesis that there is no difference in the incidence of post-obturation pain of single-visit versus multiple-visit non-surgical endodontic therapies at one day and seven days after obturation is supported by the results of this randomised clinical trial. This lack of difference suggests that single-visit treatment is an acceptable alternative to the conventional multiple-visit treatment when post-obturation discomfort is the concern. Regarding the success rate, a recent systematic review concluded that the success rates of single-visit and multiple-visit non-surgical endodontic therapies are similar [2]. If the patient can endure a longer treatment procedure, then single-visit endodontic treatment is generally considered to be more comfortable and efficient than multiple-visit treatment.

Post-obturation pain was assessed after one day and seven days in this study. Several studies reported pain after two hours [16], four hours [17] and seven days [18, 19]. The reported incidence of pain ranged from 4 [20] to $87 \%$ [21]. Studies have shown that the pain intensity was highest on the first day and dropped afterwards [20]. Another study found that post-obturation pain could persist after seven days but that its intensity typically went down significantly [22]. Therefore, this study evaluated postobturation pain after one day and seven days. The results showed that the incidence of post-obturation pain was fairly common after one day (29\%) but that it mostly subsided after seven days.

There was no significant difference in the incidence of post-obturation pain between single-visit and multiplevisit treatments, which is in agreement with previous studies [1, 18, 19, 23-33]. Furthermore, this study found that post-obturation pain after one day and seven days was more severe for teeth that received multiple-visit treatment than for those receiving single-visit treatment. This finding concurs with previous studies reporting that short-term post-obturation pain was significantly higher 
Table 4 Multi-way ANCOVA on post-obturation pain intensity after 1 day $(n=156)\left({ }^{*}\right.$ Significant result, $\left.p<0.05\right)$

\begin{tabular}{|c|c|c|c|c|c|c|}
\hline \multirow[t]{2}{*}{ Independent variable } & \multicolumn{3}{|c|}{ Unadjusted model } & \multicolumn{3}{|c|}{ Adjusted model } \\
\hline & Estimate & $95 \%$ C.I. & $p$-value & Estimate & $95 \%$ C.I. & $p$-value \\
\hline Single-visit & -0.80 & $-1.34--0.27$ & $<0.01^{*}$ & -0.79 & $-1.34--0.23$ & $0.01^{*}$ \\
\hline Thermafil (Obturation method) & 0.78 & $0.20-1.36$ & $0.01^{*}$ & 0.96 & $0.32-1.60$ & $<0.01^{*}$ \\
\hline Use of loupe & 0.68 & $0.15-1.22$ & $0.01^{*}$ & 0.33 & $-0.23-0.90$ & 0.24 \\
\hline Operator's experience $<=10$ years & -0.58 & $-1.17-0.01$ & 0.05 & & & \\
\hline Male (Gender) & 0.10 & $-0.45-0.66$ & 0.71 & & & \\
\hline Upper teeth & 0.07 & $-0.48-0.63$ & 0.79 & & & \\
\hline Anterior teeth & -0.19 & $-0.85-0.47$ & 0.58 & & & \\
\hline Single canal & 0.34 & $-0.22-0.9$ & 0.23 & & & \\
\hline C-shaped canal & -1.20 & $-2.42-0.02$ & 0.05 & & & \\
\hline Periodontal pocket & 0.30 & $-0.58-1.17$ & 0.50 & & & \\
\hline Apical periodontitis & 0.34 & $-0.30-0.99$ & 0.29 & & & \\
\hline Tender to percussion & 0.66 & $0.11-1.21$ & $0.02^{*}$ & -0.5 & $-1.19-0.19$ & 0.15 \\
\hline Hypermobility & 0.35 & $-1.20-1.90$ & 0.66 & & & \\
\hline Abscess or sinus tract & 1.75 & $0.67-2.83$ & $<0.01^{*}$ & 1.49 & $0.42-2.56$ & $0.01^{*}$ \\
\hline Tooth vitality & -0.50 & $-1.04-0.04$ & 0.07 & & & \\
\hline Opposing tooth & 1.31 & $-0.09-2.72$ & 0.07 & & & \\
\hline Age & 0.00 & $-0.01-0.02$ & 0.68 & & & \\
\hline Pre-operative pain intensity & 0.12 & $0.04-0.20$ & $<0.01^{*}$ & 0.11 & $0.02-0.20$ & $0.02^{*}$ \\
\hline Treatment time & 0.01 & $0.00-0.02$ & 0.11 & & & \\
\hline
\end{tabular}

Table 5 Post-obturation pain intensity after 7 days $(n=25)$

\begin{tabular}{lccc}
\hline Independent variable & Estimate & $95 \%$ C.I. & $p$-value \\
\hline Single-visit & -1.72 & $-3.17--0.27$ & $0.02{ }^{*}$ \\
Thermafil (Obturation method) & -0.17 & $-1.82-1.48$ & 0.84 \\
Use of loupe & 0.33 & $-1.31-1.98$ & 0.68 \\
Operator's experience $<=10$ years & 0.17 & $-1.48-1.82$ & 0.84 \\
Male (Gender) & 0.00 & $-1.65-1.65$ & 1.00 \\
Upper teeth & 0.12 & $-2.09-2.33$ & 0.91 \\
Anterior teeth & -0.25 & $-2.27-1.77$ & 0.80 \\
Single canal & 0.50 & $-1.14-2.14$ & 0.53 \\
C-shaped canal & $N A^{a}$ & & \\
Periodontal pocket & -1.25 & $-3.20-0.70$ & 0.20 \\
Apical periodontitis & 1.15 & $-0.58-2.88$ & 0.18 \\
Tender to percussion & -0.13 & $-1.75-1.49$ & 0.87 \\
Hypermobility & 0.08 & $-2.41-2.57$ & 0.95 \\
Abscess or sinus tract & 1.96 & $-0.07-4.00$ & 0.06 \\
Tooth vitality & -1.15 & $-2.70-0.39$ & 0.14 \\
Opposing tooth & 1.67 & $-2.40-5.73$ & 0.41 \\
Age & -0.04 & $-0.08-0.00$ & 0.06 \\
Pre-operative pain intensity & -0.08 & $-0.38-0.21$ & 0.56 \\
Treatment time & 0.00 & $-0.02-0.02$ & 0.80 \\
\hline O & & &
\end{tabular}

${ }^{\mathrm{a} N o t}$ applicable; no C-shaped canal found on the 25 patients; *Significant result, $\mathrm{p}<0.05$ in patients receiving multiple-visit endodontic treatment than in patients receiving single-visit treatment [34, 35].

In this study, calcium hydroxide - the most commonly used intra-canal medicament - was used. Studies have reported no significant difference in post-obturation pain with the use of calcium hydroxide compared to the use of other intra-canal medicaments [36, 37]. Sodium hypochlorite solution was used for irrigation. Bashetty and Hegde reported that the type of irrigant used had no association with the post-obturation pain after one day or after seven days [38]. Another study found no relationships between the incidence of post-obturation pain and the two working-length determination methods - via electronic apex locator and digital radiography [39]. Rotary instruments with nickel-titanium files were used in this clinical trial. Several studies reported that the incidence of post-obturation pain after rotary canal preparation was less than after preparation with manual instrumentation [40-42]. However, post-obturation pain, if any, could last longer with rotary preparation than with hand instrumentation [40]. Aqrabawi and Jamani did not find significant differences in post-obturation pain using stainless steel versus nickel-titanium endodontic files [43]. Silva and colleagues found that foraminal enlargement would not significantly affect post-obturation pain [44]. 
The purpose of this study was to compare the incidence of post-obturation pain for single-visit and multiple-visit primary non-surgical endodontic treatments. A number of confounding factors were recorded. Logistic regression was performed to explore their association with the incidence and intensity of post-obturation pain. These factors include gender, age, the operator's experience, obturation method, use of loupe, arch (upper or lower), tooth position (anterior or posterior), presence of an opposing tooth, C-shaped canal, and tooth status (which includes tooth vitality, the presence of a periodontal pocket, apical periodontitis, percussion tenderness, hypermobility, and abscess or sinus tract). There was no significant difference in post-obturation pain based on age or gender in this study, which is supported by other clinical studies [35, 45]. Some potential confounding factors, such as the quality of obturation and canal adaptation, were not recorded or analysed in this study. Due to this limitation, this study's results should be interpreted with care.

In this study, obturation with TF reduced the incidence of post-obturation pain after one day. It was plausible that significantly less obturation force was used in Thermafil obturation than in cold lateral condensation $[46,47]$. However, the pain associated with Thermafil obturation may have higher intensity than that of cold lateral condensation. The results agreed with a previous study finding that Thermafil resulted in significantly higher levels of pain than cold lateral condensation [16]. Albashaireh and Alnegrish reported that endodontic treatment on non-vital teeth had a higher chance of developing post-obturation pain than on vital teeth [33]; however, Gotler and colleagues reported the opposite, with more post-obturation pain in vital teeth [48]. We could not find a significant association between post-obturation pain and the tooth's vitality status. These findings agreed with several previous studies [20, 24, 26, 27, 35, 49]. This study also found that there was no significant association between post-obturation pain and the number of roots, which was in agreement with the studies by Raju et al. and Wang et al. [18, 24].

This study found no relationship between postobturation pain and the condition of opposing teeth, which agreed with a previous study [50]. Several studies reported that mandibular teeth had a higher chance of post-obturation pain [51, 52]; however, we found more post-obturation pain in maxillary teeth after seven days. We found more severe post-obturation pain after one day in teeth with no apical periodontitis, which was in agreement with a previous study [29]. The phenomenon might be explained by a lack of available periapical space for resolution after inflammation [29]. This study found that teeth with pre-operative pain increased the risk of post-obturation pain, which was in agreement with previous studies [20, 29, 35, 45, 51, 53-57].
There was no significant difference in post-obturation pain or pain intensity due to the operator's experience. It was interesting to find contradicting results regarding the effects of the operator's experience on post-obturation pain. One study reported significantly lower post-obturation pain among patients of undergraduate operators compared with those of residents or faculty members due to the extended time spent working on disinfecting canals during instrumentation [58]. Another study reported no significant difference in post-obturation pain due to the operator's experience. The differences found in the above studies did not take into consideration the cases' relative difficulty.

It is generally agreed that the operator's clinical experience will affect the success rate and post-obturation pain. However, this study found no association between operator's experience and post-obturation pain or pain intensity. Law and colleagues found that the effect of clinical experience on post-obturation pain was difficult to determine [57]. The choice between single-visit and multiple-visit treatments was based on the operator's skill. Some clinicians have suggested multiple-visit treatment when in doubt. For communities where patients tended to fail to attend subsequent appointments once the pain was relieved on the first appointment, singlevisit treatment is regarded as a safe and effective alternative to incomplete multiple-visit treatment [59].

\section{Conclusions}

In this randomised clinical trial, post-obturation pain after non-surgical endodontic therapy was not uncommon after one day (29\%), but only $5 \%$ of teeth had pain after seven days. There was no significant difference in the incidences of post-obturation pain after one day and seven days among single-visit and multiple-visit endodontic treatments. Among the teeth with post-obturation pain, the single-visit group had lower-intensity pain, after one day and after seven days, than the multiple-visit group had.

\section{Competing interests}

The authors declare that they have no competing interests.

\section{Authors' contributions}

AWYW was the primary researcher in Hong Kong. XZ was the project dentist in charge in Beijing. SZ provided general support. SKYL performed the statistical analysis. CZ and CHC planned and supervised the study. All of the authors read and approved the final manuscript.

\section{Authors' information}

Dr AWY Wong is a dental surgeon, Dr S Zhang is the project co-ordinator, Ms SKY $\mathrm{Li}$ is a statistician, and Drs CH Chu and C Zhang are clinical associate professors, all in the Faculty of Dentistry, The University of Hong Kong. Dr X Zhu is a clinical associate professor in the School and Hospital of Stomatology, Peking University.

\section{Acknowledgements}

The authors wish to thank the participating patients and staff at HKU Health Service Dental Clinic in Hong Kong and the PKU School and Hospital of Stomatology VIP Dental Service \& Geriatric Dentistry Clinic in Beijing for their support in this study. 
Received: 10 January 2015 Accepted: 7 August 2015 Published online: 14 August 2015

\section{References}

1. DiRenzo A, Gresla T, Johnson BR, Rogers M, Tucker D, BeGole EA. Postoperative pain after 1- and 2-visit root canal therapy. Oral Surg Oral Med Oral Pathol Oral Radiol Endod. 2002;93(5):605-10.

2. Wong AW, Zhang $\mathrm{C}$, Chu $\mathrm{CH}$. A systematic review of nonsurgical single-visit versus multiple-visit endodontic treatment. Clin Cosmet Invest Dent. 2014;6:45-56.

3. Fleming $\mathrm{CH}$, Litaker MS, Alley LW, Eleazer PD. Comparison of classic endodontic techniques versus contemporary techniques on endodontic treatment success. J Endod. 2010;36(3):414-8.

4. Chu CH, Lo EC, Cheung GS. Outcome of root canal treatment using Thermafil and cold lateral condensation filling techniques. Int Endod J. 2005;38(3):179-85.

5. Zheng QZ, Wang J, Liu LM. [Comparison of the clinical effects of three root canal treatments.]. Shanghai Kou Qiang Yi Xue. 2004;13(5):459-61.

6. Mohan SM, Kaushik SK. Root canal treatment using thermoplasticized carrier condensation technique. Med J Armed Forces India. 2009;65(4):336-41.

7. Samadi F, Jaiswal J, Saha S, Garg N, Chowdhary S, Samadi F, et al. A comparative evaluation of efficacy of different obturation techniques used in root canal treatment of anterior teeth: an in vitro study. Int J Clin Pediatr Dent. 2014;7(1):1-5.

8. Gencoglu N, Garip Y, Bas M, Samani S. Comparison of different gutta-percha root filling techniques: Thermafil, Quick-fill, System B, and lateral condensation. Oral Surg Oral Med Oral Pathol Oral Radiol Endod. 2002;93(3):333-6.

9. Clinton K, Van Himel T. Comparison of a warm gutta-percha obturation technique and lateral condensation. J Endod. 2001;27(11):692-5.

10. Goldberg F, Artaza LP, De Silvio A. Effectiveness of different obturation techniques in the filling of simulated lateral canals. J Endod. 2001;27(5):362-4.

11. Gilbert SD, Witherspoon DE, Berry CW. Coronal leakage following three obturation techniques. Int Endod J. 2001;34(4):293-9.

12. Chu CH, Lo EC. Immediate post-application effect of professional prophylaxis with $8 \%$ arginine-calcium carbonate desensitizing paste on hypersensitive teeth. A practitioner-based clinical trial. Am J Dent. 2014;27(1):7-11.

13. El Karim I, Kennedy J, Hussey D. The antimicrobial effects of root canal irrigation and medication. Oral Surg Oral Med Oral Pathol Oral Radiol Endod. 2007:103(4):560-9.

14. labal MK, Kim S. A review of factors influencing treatment planning decisions of single-tooth implants versus preserving natural teeth with nonsurgical endodontic therapy. J Endod. 2008;34(5):519-29.

15. Watkins CA, Logan HL, Kirchner HL. Anticipated and experienced pain associated with endodontic therapy. J Am Dent Assoc. 2002;133(1):45-54.

16. Alonso-Ezpeleta LO, Gasco-Garcia C, Castellanos-Cosano L, Martin-Gonzalez J, Lopez-Frias FJ, Segura-Egea JJ. Postoperative pain after one-visit rootcanal treatment on teeth with vital pulps: comparison of three different obturation techniques. Med Oral Patol Oral Cir Bucal. 2012;17(4):e721-7.

17. Atbaei A, Mortazavi N. Prophylactic intraligamentary injection of piroxicam (feldene) for the management of post-endodontic pain in molar teeth with irreversible pulpitis. Aust Endod J. 2012;38(1):31-5.

18. Raju TB, Seshadri A, Vamsipavani B, Abhilash K, Subhash AV, Kumari KV. Evaluation of pain in single and multi rooted teeth treated in single visit endodontic therapy. J Int Oral Health. 2014;6(1):27-32.

19. Rao KN, Kandaswamy R, Umashetty G, Rathore VP, Hotkar C, Patil BS Post-Obturation pain following one-visit and two-visit root canal treatment in necrotic anterior teeth. J Int Oral Health. 2014;6(2):28-32.

20. Ali SG, Mulay S, Palekar A, Sejpal D, Joshi A, Gufran H. Prevalence of and factors affecting post-obturation pain following single visit root canal treatment in Indian population: A prospective, randomized clinical trial. Contemp Clin Dent. 2012;3(4):459-63.

21. Alonso-Ezpeleta O, Martin PJ, Lopez-Lopez J, Castellanos-Cosano L, Martin-Gonzalez J, Segura-Egea JJ. Pregabalin in the treatment of inferior alveolar nerve paraesthesia following overfilling of endodontic sealer. J Clin Exp Dent. 2014;6(2):e197-202.

22. Pak JG, White SN. Pain prevalence and severity before, during, and after root canal treatment: a systematic review. J Endod. 2011;37(4):429-38.
23. Prashanth MB, Tavane PN, Abraham S, Chacko L. Comparative evaluation of pain, tenderness and swelling followed by radiographic evaluation of periapical changes at various intervals of time following single and multiple visit endodontic therapy: an in vivo study. J Contemp Dent Pract. 2011;12(3):187-91.

24. Wang C, Xu P, Ren L, Dong G, Ye L. Comparison of post-obturation pain experience following one-visit and two-visit root canal treatment on teeth with vital pulps: a randomized controlled trial. Int Endod J. 2010;43(8):692-7.

25. El Mubarak AH, Abu-bakr NH, Ibrahim YE. Postoperative pain in multiple-visit and single-visit root canal treatment. J Endod. 2010;36(1):36-9.

26. Ince B, Ercan E, Dalli M, Dulgergil CT, Zorba YO, Colak H. Incidence of postoperative pain after single- and multi-visit endodontic treatment in teeth with vital and non-vital pulp. Eur J Dent. 2009;3(4):273-9.

27. Kalhoro FA, Mirza AJ. A study of flare-ups following single-visit root canal treatment in endodontic patients. J Coll Physicians Surg Pak. 2009:19(7):410-2

28. Sathorn C, Parashos $\mathrm{P}$, Messer $\mathrm{H}$. The prevalence of postoperative pain and flare-up in single- and multiple-visit endodontic treatment: a systematic review. Int Endod J. 2008:41(2):91-9.

29. Risso PA, Cunha AJ, Araujo MC, Luiz RR. Postobturation pain and associated factors in adolescent patients undergoing one- and two-visit root canal treatment. J Dent. 2008;36(11):928-34.

30. Figini L, Lodi G, Gorni F, Gagliani M. Single versus multiple visits for endodontic treatment of permanent teeth. Cochrane Database Syst Rev. 2007(4):Cd005296. doi:10.1002/14651858.CD005296.pub2.

31. Lin NY, Gao XJ. [A short-term clinical study of one-visit endodontic treatment for infected root canals]. Zhonghua Kou Qiang Yi Xue Za Zhi. 2006;41(9):525-8

32. Al-Negrish AR, Habahbeh $\mathrm{R}$. Flare up rate related to root canal treatment of asymptomatic pulpally necrotic central incisor teeth in patients attending a military hospital. J Dent. 2006:34(9):635-40.

33. Albashaireh ZS, Alnegrish AS. Postobturation pain after single- and multiple-visit endodontic therapy. A prospective study. J Dent. 1998;26(3):227-32

34. Su Y, Wang C, Ye L. Healing rate and post-obturation pain of single- versus multiple-visit endodontic treatment for infected root canals: a systematic review. J Endod. 2011;37(2):125-32.

35. Tanalp J, Sunay H, Bayirli G. Cross-sectional evaluation of post-operative pain and flare-ups in endodontic treatments using a type of rotary instruments. Acta Odontol Scand. 2013;71(3-4):733-9.

36. Gesi A, Hakeberg M, Warfvinge J, Bergenholtz G. Incidence of periapical lesions and clinical symptoms after pulpectomy-a clinical and radiographic evaluation of 1- versus 2-session treatment. Oral Surg Oral Med Oral Patho Oral Radiol Endod. 2006;101(3):379-88.

37. Walton RE, Holton Jr IF, Michelich R. Calcium hydroxide as an intracanal medication: effect on posttreatment pain. J Endod. 2003;29(10):627-9.

38. Bashetty K, Hegde J. Comparison of $2 \%$ chlorhexidine and $5.25 \%$ sodium hypochlorite irrigating solutions on postoperative pain: a randomized clinical trial. Indian J Dent Res. 2010;21(4):523-7.

39. Kara Tuncer A, Gerek M. Effect of working length measurement by electronic apex locator or digital radiography on postoperative pain: a randomized clinical trial. J Endod. 2014;40(1):38-41.

40. Arias A, de la Macorra JC. Azabal M. Peters OA. Prospective case controlled clinical study of post-endodontic pain after rotary root canal preparation performed by a single operator. Journal of dentistry: Hidalgo JJ: 2014.

41. Pasqualini D, Mollo L, Scotti N, Cantatore G, Castellucci A, Migliaretti G, et al. Postoperative pain after manual and mechanical glide path: a randomized clinical trial. J Endod. 2012;38(1):32-6.

42. Wei $X$, Lin Z, Peng S. [The effect of root canal preparation with nickeltitanium rotary instruments in reducing post-operative pain]. Hua Xi Kou Qiang Yi Xue Za Zhi. 2003:21(3):202-4

43. Aqrabawi J, Jamani K. Prevalence of post-treatment pain after cleaning and shaping of the root canal system using manual step-back versus rotary nickel titanium. Odonto-Stomatologie Tropicale. 2006;29(113):5-9.

44. Silva EJ, Menaged K, Ajuz N, Monteiro MR, Coutinho-Filho TS. Postoperative pain after foraminal enlargement in anterior teeth with necrosis and apical periodontitis: a prospective and randomized clinical trial. J Endod. 2013;39(2):173-6

45. Imura N, Zuolo ML. Factors associated with endodontic flare-ups: a prospective study. Int Endod J. 1995;28(5):261-5. 
46. Ersoy I, Evcil MS. Evaluation of the effect of different root canal obturation techniques using two root canal sealers on the fracture resistance of endodontically treated roots. Microsc Res Tech. 2015;78(5):404-7.

47. Blum JY, Machtou P, Micallef JP. Analysis of forces developed during obturations. Wedging effect: Part II. J Endod. 1998;24(4):223-8.

48. Gotler M, Bar-Gil B, Ashkenazi M. Postoperative pain after root canal treatment: a prospective cohort study. Int J Dent. 2012;2012:310467.

49. Keiser K. Magnification options in endodontics: a comparison of the operating microscope and the endoscope. Tex Dent J. 2007;124(2):208-16.

50. Parirokh M, Rekabi AR, Ashouri R, Nakhaee N, Abbott PV, Gorjestani H. Effect of occlusal reduction on postoperative pain in teeth with irreversible pulpitis and mild tenderness to percussion. J Endod. 2013;39(1):1-5.

51. Arias A, Azabal M, Hidalgo JJ, de la Macorra JC. Relationship between postendodontic pain, tooth diagnostic factors, and apical patency. J Endod. 2009:35(2):189-92

52. Alacam T, Tinaz AC. Interappointment emergencies in teeth with necrotic pulps. J Endod. 2002;28(5):375-7.

53. Glennon JP, Ng YL, Setchell DJ, Gulabivala K. Prevalence of and factors affecting postpreparation pain in patients undergoing two-visit root canal treatment. Int Endod J. 2004;37(1):29-37.

54. Torabinejad M, Dorn SO, Eleazer PD, Frankson M, Jouhari B, Mullin RK, et al. Effectiveness of various medications on postoperative pain following root canal obturation. J Endod. 1994;20(9):427-31.

55. Siqueira Jr JF, Rocas IN, Favieri A, Machado AG, Gahyva SM, Oliveira JC, et al. Incidence of postoperative pain after intracanal procedures based on an antimicrobial strategy. J Endod. 2002;28(6):457-60.

56. Polycarpou N, Ng YL, Canavan D, Moles DR, Gulabivala K. Prevalence of persistent pain after endodontic treatment and factors affecting its occurrence in cases with complete radiographic healing. Int Endod J. 2005;38(3):169-78.

57. Law AS, Nixdorf DR, Aguirre AM. Reams GJ. Manne BD et al. Predicting Severe Pain after Root Canal Therapy in the National Dental PBRN. Journal of dental research: Tortomasi AJ; 2014

58. Walton R, Fouad A. Endodontic interappointment flare-ups: a prospective study of incidence and related factors. J Endod. 1992:18(4):172-7.

59. Oginni A, Udoye Cl. Endodontic flare-ups: comparison of incidence between single and multiple visits procedures in patients attending a Nigerian teaching hospital. Odonto-Stomatologie Tropicale. 2004:27(108):23-7.

\section{Submit your next manuscript to BioMed Central and take full advantage of:}

- Convenient online submission

- Thorough peer review

- No space constraints or color figure charges

- Immediate publication on acceptance

- Inclusion in PubMed, CAS, Scopus and Google Scholar

- Research which is freely available for redistribution 